\title{
MOLECULAR CHARACTERIZATION OF IRANIAN PATIENTS WITH INHERITED COAGULATION FACTOR VII DEFICIENCY
}

\author{
Shahbazi $\mathrm{S}^{1, *}$, Mahdian $\mathrm{R}^{2}$, Karimi K${ }^{3}$, Mashayekhi $\mathrm{A}^{1}$
}

\begin{abstract}
*Corresponding Author: Dr. Shirin Shahbazi, Department of Medical Genetics, Faculty of Medical Sciences, Tarbiat Modares University, Al-e-Ahmad and Chamran Cross, POB 14115-111Tehran, Iran. Tel: +98-21-82-884-556. Fax: +98-2182-884-555. E-mail: sh.shahbazi@modares.ac.ir
\end{abstract}

\begin{abstract}
Coagulation factor VII (FVII) is a key enzyme of the extrinsic coagulation cascade that is predominantly produced by hepatocytes. The $F 7$ gene mutations cause FVII deficiency with considerable molecular and phenotypic heterogeneity. We characterized the molecular alterations of the $F 7$ gene and their corresponding mRNA transcripts in Iranian patients from eight unrelated families. The mutations were detected by polymerase chain reaction (PCR)-sequencing of all $F 7$ gene exons, their flanking intronic sequences, as well as their corresponding cDNA fragments. Homozygous P303T, C91S and R304Q mutations were detected in patient 2 , patient 5 , and patient 6 , respectively. Patient 7 was a compound heterozygote for S282R and H348R and patient 8 was a compound heterozygote for R304Q and IVS7+7A $>\mathrm{G}$ mutations. Furthermore, our investigation revealed three heterozygous individuals, patient 1 and patient 3 with the A244V mutation who were symptomatic and patient 4 with V(-39)I mutation who was also asymptomatic. The $F 7$ mRNA expression analysis revealed that, except the transcript of V(-39)I, other mutation-harboring transcripts were expressed at detectable levels. In conclusion, this report reinforces the genetic and phenotypic heterogeneity of FVII deficiency. The findings of the mRNA study implied that decreased FVII protein activity subsequent to missense mutations does not completely reflect the degradation of mutation-harboring mRNA.
\end{abstract}

Keywords: Coagulation factor VII (FVII) deficiency; F7 gene; mRNA sequencing; Mutation detection.

\footnotetext{
${ }^{1}$ Department of Medical Genetics, Faculty of Medical Sciences, Tarbiat Modares University Tehran, Iran

${ }^{2}$ Molecular Medicine Department, Pasteur Institute of Iran, Tehran, Iran

${ }^{3}$ Clinic of Hematology and Oncology, School of Medical Sciences, Tehran University of Medical Sciences, Tehran, Iran
}

\section{INTRODUCTION}

Coagulation factor VII (FVII) is a vitamin K-dependent serine protease that has a key role in the initiation of the coagulation cascade. This factor circulates in the blood at a concentration of $0.5 \mu \mathrm{g} / \mathrm{mL}$ and its severe reduction leads to rare autosomal recessive bleeding disorder, FVII deficiency $[1,2]$. The $F 7$ gene maps to the long arm of chromosome 13 (13q34) and contains nine exons [1,3]. It is expressed as two major transcripts, $\mathrm{A}$ and $\mathrm{B}$, each $\sim 3.1 \mathrm{~kb}$ long, that encode polypeptides of 466 and 444 residues, respectively [4]. The pre proteins are synthesized with either 60 or 38 amino acid leader sequences that yield a unique mature single chain protein of 406 amino acids with a molecular weight of $\sim 50 \mathrm{kDa}$. Exons 1a, $1 \mathrm{~b}$ and a fraction of exon 2 encode the leader sequences, the rest of exon 2 and exons 3 to 8 encode the mature protein [5]. Upon blood vessel injury, tissue factor is exposed to the circulation and interacts with FVII and activates it by cleavage between $\operatorname{Arg} 152$ and Ile153. The activated FVII (FVIIa) consists of a 254-residue heavy chain that contains a catalytic domain and is linked by a disulfide bond to a 152-residue light chain that contains two epidermal growth factor-like (EGF-like) domains [6].

The most common FVII deficiency symptoms consist of soft tissue, mucocutaneous, joint and gastrointestinal hemorrhage. The hereditary form of the disease shows considerable phenotypic heterogeneity ranging from lethal to mild or even asymptomatic types. As a result, prevalence and incidence of FVII deficiency is not entirely determined [7]. Studies show that the incidence of clinically significant FVII deficiencies is estimated to be $1 / 500,000$ [8]. However, the disease is more frequent where consanguineous marriages are commonplace [9]. The severity of hemorrhagic symptoms is not directly related to the level of plasma FVII coagulant activity $[2,10]$. In a study on 717 patients, Herrmann et al. [11] reported that about $60.0 \%$ 
of FVII deficient patients were asymptomatic who were diagnosed following an abnormal prothrombin time (PT) test. They also mentioned that the causative mutations responsible for FVII deficiency are spread throughout the F7 gene with no well-defined hot-spots. More than 250 mutations have been reported with FVII deficiency with missense mutations as the most frequent type. Exon 8 is the largest exon of the $F 7$ gene that accommodates the highest number of mutations [12]. The most severe cases are either homozygous or compound heterozygous resulting in FVII:C levels less than $2.0 \%$ of normal. Occasionally, heterozygous carriers display hemorrhagic symptoms that can be severe in rare cases. Recently, a heterozygous patient was reported with severe spontaneous intra cranial bleeding. He was a previously healthy 19 -year-old patient, without any reported hemorrhagic symptoms, even following tonsillectomy in childhood [13].

We here report on the characterization of the mutations in eight patients from eight unrelated families in Iran. We also intended to elucidate the effect of each mutation on their corresponding mRNA expression.

\section{MATERIALS AND METHODS}

Patients and Sample Collection. This study was approved by the ethics committee of the Iran National Science Foundation (INSF). Eight FVII deficiency patients participated in this study after we obtained written informed consent. They were selected from eight unrelated families living in different parts of Tehran Province, Iran. The patients were referred to the Clinic of Hematology and Oncology, Imam Khomeini Hospital in Tehran, Iran. All of them were evaluated by a hematologist for clinical manifestation and tested for bleeding abnormalities and coagulation factor levels.

For DNA and RNA extraction, $5 \mathrm{~mL}$ of peripheral blood was collected from each patient in EDTA-containing vacutainers. Each sample was divided into two aliquots, one to be used for peripheral blood mononuclear cells (PBMCs) and RNA isolation and the other for DNA extraction. In order to separate PBMCs, the blood samples were centrifuged at $150 \mathrm{~g}$ for $20 \mathrm{~min}$. and the plasma content (upper phase) was removed. The cells in the lower phase were resuspended $(1: 2 \mathrm{~V} / \mathrm{V})$ with phosphate-buffered saline (PBS), overlaid on Ficoll-Plaque ${ }^{\mathrm{TM}}$ (Sigma-Aldrich Co. Ltd., Gillingham, Dorset, UK) and centrifuged at 400 $\mathrm{g}$ for $30 \mathrm{~min}$. at room temperature. The PBMC layer were collected and stored at $-80^{\circ} \mathrm{C}$ until used for RNA isolation.

DNA Extraction and Mutation Detection. Genomic DNA was extracted from the whole blood samples using a salting-out method. The concentration and purity of the isolated DNA were determined by a spectrophotometer (Nanophotometer ${ }^{\mathrm{TM}}$; Implen GmbH, München, Germany). High quality DNA (A260/280 $\geq 1.8)$ was selected and kept at $-20{ }^{\circ} \mathrm{C}$.

The primers were designed to amplify all $F 7$ gene exons and their flanking intronic sequences using Oligo explorer (Gene Link Inc., Hawthorne, NY, USA) software (V 1.2) and verified for specificity using the BLAST website (https://www.ncbi.nlm.nih.gov/tools/primer-blast/). The sequence of the primers and their polymerase chain reaction (PCR) product size are described in Table 1.

Polymerase chain reactions included $0.4 \mu \mathrm{M}$ of each primer and $50 \mathrm{ng}$ of genomic DNA in $2 \times \mathrm{PCR}$ master mix (Ampliqon; Pishgam Biotech, Tehran, Iran ) containing 0.2 units $/ \mu \mathrm{L}$ Ampliqon Taq DNA polymerase and $2.5 \mathrm{mM}$ $\mathrm{MgCl}_{2}$. The PCR amplification involved an initial denaturation step for $5 \mathrm{~min}$. at $94{ }^{\circ} \mathrm{C}$ and 30 cycles of 30 seconds at $94{ }^{\circ} \mathrm{C}$, primer annealing temperature for 30 seconds and $72{ }^{\circ} \mathrm{C}$ for $1 \mathrm{~min}$., followed by a final extension step at 72 ${ }^{\circ} \mathrm{C}$ for $5 \mathrm{~min}$. Amplified fragments were sequenced and the data were analyzed using Chromas software (http:// technelysium.com.au/wp/chromas/). All sequence changes were confirmed on both strands.

RNA Extraction and Reverse Transcription-Polymerase Chain Reaction (RT-PCR). RNA was extracted from PBMC pellets using NucleoSpin ${ }^{\circledR}$ RNA Blood kit (Macherey-Nagel; Bahar-Tashkhis, Tehran, Iran) as recommended by the manufacturer. The concentration and purity of the purified RNA were determined by spectrophotometry and gel electrophoresis. High quality RNA (A260/280 $\geq 1.8$ ) was selected and kept at $-80{ }^{\circ} \mathrm{C}$ until used for cDNA synthesis. Up to $1 \mu \mathrm{g}$ RNA was converted to cDNA using RevertAid First Strand cDNA synthesis kit (Thermo Scientific; NedayeFan Company, Tehran, Iran) according to the manufacturer's instructions. To verify the integrity of the cDNA, a RT-PCR experiment was performed using GAPDH gene specific primers.

The purified cDNA was subjected to amplification and sequencing. The primers were designed by Oligo explorer software (V 1.2) and specified using the BLAST website as described in Table 2. Reverse transcription-polymerase chain reactions were performed in a final volume of $25 \mu \mathrm{L}$ containing $2 \mu \mathrm{L}$ of cDNA, $1 \mu \mathrm{L}$ of each primer in $2 \times \mathrm{PCR}$ master mix. The RT-PCR amplification program started with a single denaturation step at $94{ }^{\circ} \mathrm{C}$ for $5 \mathrm{~min}$. and followed by 30 cycles of 30 seconds at $94{ }^{\circ} \mathrm{C}$, primer annealing temperature for 30 seconds and $72{ }^{\circ} \mathrm{C}$ for $1 \mathrm{~min}$., followed by a final extension step at $72{ }^{\circ} \mathrm{C}$ for $5 \mathrm{~min}$. Amplified fragments were analyzed by DNA sequencing to 
determine the proportion of mutation-containing transcript. Relative allele-specific mRNA quantitation by DNA sequencing was carried out as described previously [14,15].

\section{RESULTS}

Patients. Table 3 shows clinical information and FVII activity levels of each patient. As shown, the severity of symptoms was not directly correlated with FVII activity levels. Chronic nosebleeds, easy bruising and bleeding from the gums were the most common symptoms. Patient 4 was the only asymptomatic patient in our study. He was diagnosed following pre surgery blood analysis. Patient 3 was a female patient who developed menorrhagia as the main clinical manifestation. Patient 2 and patient 6 were born from consanguineous marriages.

F7 Mutation Status Detected by Polymerase Chain Reaction-Sequencing. Eight different $F 7$ gene mutations were detected in our study patients. The mutations and their corresponding amino acid changes are summarized in Table 4. Homozygous P303T, C91S and R304Q mutations were detected in patient 2 , patient 5 and patient 6 , respectively. Patient 7 was a compound heterozygote for S282R and H348R. Another compound heterozygous mutation was detected in patient 8 with R304Q and IVS7+7A $>$ G alterations. Furthermore, our investigation revealed three heterozygous individuals, patient 1 and patient 3 with the A244V mutation who were symptomatic and patient 4 with $\mathrm{V}(-39) \mathrm{I}$ mutation who was asymptomatic.

The $\boldsymbol{F} 7$ cDNA Analysis. Despite the low level of $F 7$ transcript in peripheral blood cells, the extraction and amplification of $F 7$ mRNA were successfully performed. We expected the amplification of alternative isoforms of $F 7$ mRNA according to the presence or absence of exon 1b. Although the only observed mRNA isoform was the transcript lacking exon $1 \mathrm{~b}$.

Table 1. Characteristics of the primer sets used for the polymerase chain reaction assay.

\begin{tabular}{|c|c|c|c|}
\hline Oligo Primers & Sequences $\left(5^{\prime}>3^{\prime}\right)$ & Tm & Amplicon (bp) \\
\hline $\begin{array}{l}\text { F71aF } \\
\text { F71aR }\end{array}$ & $\begin{array}{l}\text { GAA CTT TGC CCG TCA GTC CC } \\
\text { CCG CCA GAA AAC CCT CCT G }\end{array}$ & 61 & 258 \\
\hline $\begin{array}{l}\text { F71bF } \\
\text { F71bR }\end{array}$ & $\begin{array}{l}\text { GAC AGT GCC TGG GAT GTG G } \\
\text { GAG CGG TCA CTT CCT CTC GA }\end{array}$ & 60 & 293 \\
\hline $\begin{array}{l}\text { F72F } \\
\text { F72R }\end{array}$ & $\begin{array}{l}\text { GGG AAG GAT GGG CGA CGG } \\
\text { CCA GGA AAG CGG AGT CAC CC }\end{array}$ & 62 & 534 \\
\hline $\begin{array}{l}\text { F734F } \\
\text { F734R }\end{array}$ & $\begin{array}{l}\text { TGT CCA GTG CTT ACC GTT GG } \\
\text { AAT TTC CAA CTG GGG CTG AG }\end{array}$ & 59 & 419 \\
\hline $\begin{array}{l}\text { F75F } \\
\text { F75R }\end{array}$ & $\begin{array}{l}\text { GAT CAG TCC ACG GAG CAG G } \\
\text { GTA GAT GTG AAG CCA CTC CC }\end{array}$ & 58 & 408 \\
\hline $\begin{array}{l}\text { F76F } \\
\text { F76R }\end{array}$ & $\begin{array}{l}\text { CTG AAT CTT TCC TAG TGG CAC G } \\
\text { CAA AAG GCT TCA AGA CCC TCA G }\end{array}$ & 59 & 235 \\
\hline $\begin{array}{l}\text { F77F } \\
\text { F77R }\end{array}$ & $\begin{array}{l}\text { AGC AAT GTG ACT TCC ACA CC } \\
\text { AGC CCC CAG TCT TTT ATC GT }\end{array}$ & 58 & 543 \\
\hline $\begin{array}{l}\text { F78aF } \\
\text { F78aR }\end{array}$ & $\begin{array}{l}\text { CCC AGA CCC CAG ATT CAC CC } \\
\text { GCC TCC ACT GTC CCC CTT G }\end{array}$ & 62 & 633 \\
\hline $\begin{array}{l}\text { F78bF } \\
\text { F78bR }\end{array}$ & $\begin{array}{l}\text { AGT CAC GGA AGG TGG GAG AC } \\
\text { GGG ATT TGG TGC CAG GAC AG }\end{array}$ & 61 & 349 \\
\hline
\end{tabular}

F: forward; R: reverse.

Table 2. Characteristics of the primer sets used for the reverse transcription-polymerase chain reaction assay.

\begin{tabular}{|l|l|c|c|}
\hline Oligo Primers & Sequences (5'>3') & Tm & Amplicon (bp) \\
\hline F7cD1F & CAA CAG GCA GGG GCA GCA C & 63 & 303 \\
F7cD1R & TCG TGG CAC CGA CAG GAG C & 60 & 680 \\
\hline F7cD2F & TGT GTG AAC GAG AAC GGC G & & \\
F7cD2R & ACC TTC CGT GAC TGC TGC & 62 & 591 \\
\hline F7cD3F & ATG TGG TGC CCC TCT GCC & & \\
F7cD3R & TGT CTC TGT CTC CCT CCC CA & & \\
\hline
\end{tabular}

F: forward; R: reverse. 
Direct sequencing of PBMC-derived cDNA for A244V, S282K, H348Q and R304Q mutations revealed equal expression of wild-type and mutant allele transcripts. These variants were detected in the compound heterozygous and heterozygous patients. In addition, the cDNA analysis in homozygous patients indicated that mutationharboring transcripts, i.e., P303T, C91S and R304Q, were also detectable. In contrast, cDNA sequencing of the $64 \mathrm{G}>$ A heterozygote mutation showed the absence of the mutated allele transcript in patient 4 . The sequencing chromatogram shown in Figure 1 presents $64 \mathrm{G}>\mathrm{A}$ in the genomic DNA and its absence in the corresponding cDNA. Evaluation of transcript following the IVS7 $+7 \mathrm{~A}>\mathrm{G}$ variant that was detected in patient 8 showed a cDNA with normal pattern.

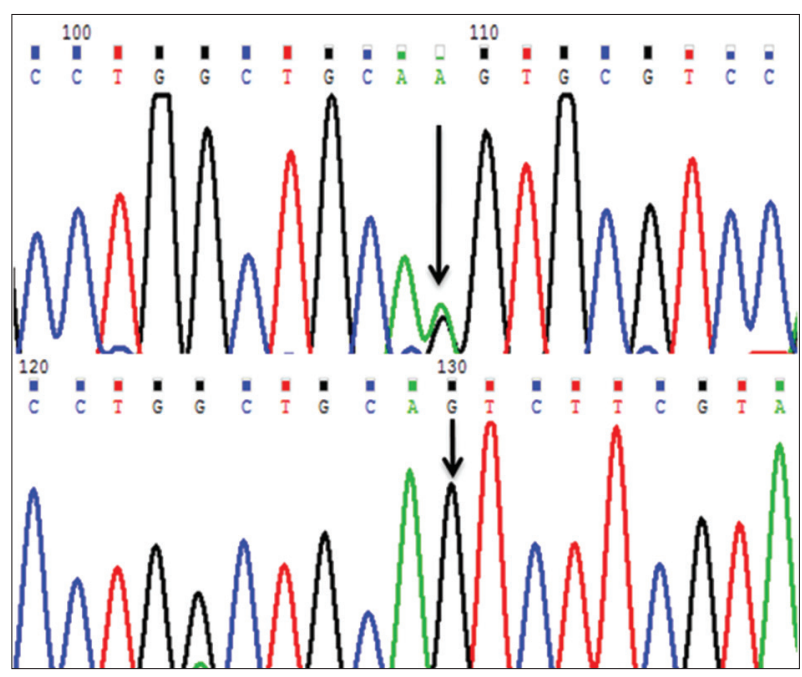

Figure 1. The sequencing chromatogram of $64 \mathrm{G}>\mathrm{A}$ in genomic DNA (upper) and cDNA (lower) of patient 4.

Table 3. Patient characteristics, symptoms and plasma FVII coagulation activity (FVII:C).

\begin{tabular}{|l|c|c|c|l|}
\hline Patient & Sex-Age & Consanguinity & FVII:C (IU/dL) & \multicolumn{1}{|c|}{ Hemorrhagic Symptoms } \\
\hline Patient 1 & M-22 & no & $18.0 \%$ & $\begin{array}{l}\text { gastrointestinal bleeding, epistaxis, oral cavity } \\
\text { bleeding, cutaneous symptoms }\end{array}$ \\
\hline Patient 2 & M-34 & yes & $7.0 \%$ & $\begin{array}{l}\text { hemarthrosis, epistaxis, oral cavity bleeding, } \\
\text { cutaneous symptoms }\end{array}$ \\
\hline Patient 3 & F-32 & no & $33.0 \%$ & $\begin{array}{l}\text { menorrhagia, epistaxis, oral cavity bleeding, } \\
\text { cutaneous symptoms }\end{array}$ \\
\hline Patient 4 & M-54 & no & $29.0 \%$ & asymptomatic \\
\hline Patient 5 & M-20 & NA & $2.0 \%$ & cutaneous symptoms, epistaxis, oral cavity bleeding \\
\hline Patient 6 & M-67 & yes & $16.0 \%$ & epistaxis, oral cavity bleeding, cutaneous symptoms \\
\hline Patient 7 & M-26 & no & $<1.0 \%$ & $\begin{array}{l}\text { hemathrosis, epistaxis, oral cavity bleeding, } \\
\text { cutaneous symptoms }\end{array}$ \\
\hline Patient 8 & M-31 & no & $25.0 \%$ & $\begin{array}{l}\text { gastrointestinal bleeding, epistaxis, oral cavity } \\
\text { bleeding, cutaneous symptoms }\end{array}$ \\
\hline
\end{tabular}

NA: not applicable.

Table 4. The F7 mutation locations and corresponding nucleotide and amino acid changes in the study patients. The indicated variants in parentheses are in Human Genome Variation Society (HGVS) format.

\begin{tabular}{|c|c|c|c|c|c|}
\hline Patient & Exon & Nucleotide Change & $\begin{array}{c}\text { Amino Acid } \\
\text { Change }\end{array}$ & Genotype & $\begin{array}{c}\text { MutationTaster2 } \\
\text { Prediction }^{\mathrm{a}}\end{array}$ \\
\hline Patient 1 & 8 & g. $10648 \mathrm{C}>\mathrm{T}(\mathrm{g} .12728 \mathrm{C}>\mathrm{T})(\mathrm{GCG}>\mathrm{G} T \mathrm{G})$ & $\mathrm{A} 244 \mathrm{~V}(\mathrm{~A} 282 \mathrm{~V})$ & heterozygote & disease causing score: 64 \\
\hline Patient 2 & 8 & g.10824C $>$ A (g.12904C $>$ A $)(C C C>A C C)$ & P303V (P341T) & homozygote & disease causing score: 38 \\
\hline Patient 3 & 8 & g.10648C $>$ T $($ g. $12728 \mathrm{C}>\mathrm{T})(\mathrm{GCG}>\mathrm{GTG})$ & $\mathrm{A} 244 \mathrm{~V}(\mathrm{~A} 282 \mathrm{~V})$ & heterozygote & disease causing score: 64 \\
\hline Patient 4 & $1 \mathrm{a}$ & g.64G $>\mathrm{A}(\mathrm{g} .115 \mathrm{G}>\mathrm{A})(G \mathrm{TC}>A \mathrm{TC})$ & $\mathrm{V}(-39) \mathrm{I}(\mathrm{V} 22 \mathrm{I})$ & heterozygote & disease causing score: 29 \\
\hline Patient 5 & 5 & g. $7807 \mathrm{G}>\mathrm{C}($ g. $9891 \mathrm{G}>\mathrm{C})(\mathrm{T} G \mathrm{~T}>\mathrm{TCT})$ & C91S (C129S) & homozygote & disease causing score: 112 \\
\hline Patient 6 & 8 & g.10828G $>$ A (g.12908G $>$ A $)(C G G>C A G)$ & R304Q (R342Q) & homozygote & disease causing score: 43 \\
\hline \multirow{2}{*}{ Patient 7} & 8 & g.10763C $>$ G (g.12843C $>$ G) $(A G C>A G G)$ & S282R (S320R) & compound & disease causing score: 110 \\
\hline & 8 & g. $10960 \mathrm{~A}>\mathrm{G}(\mathrm{g} .13040 \mathrm{~A}>\mathrm{G})(\mathrm{C} A \mathrm{~T}>\mathrm{C} G \mathrm{~T})$ & H348R (H386R) & heterozygote & disease causing score: 29 \\
\hline \multirow{2}{*}{ Patient 8} & 8 & g.10828G $>$ A $($ g. $12908 \mathrm{G}>\mathrm{A})(\mathrm{C} G \mathrm{G}>\mathrm{C} A \mathrm{G})$ & R304Q (R342Q) & compound & disease causing score: 43 \\
\hline & Intron 7 & g. $9733 \mathrm{~A}>\mathrm{G}(\mathrm{IVS} 7+7 \mathrm{~A}>\mathrm{G})$ & - & heterozygote & disease causing score: - \\
\hline
\end{tabular}

a The disease causing scores of the mutations were determined using the MutationTaster2 online software (http:// www.mutationtaster.org/). 


\section{DISCUSSION}

Identification of underlying gene alterations and their expression changes can be a prerequisite for the proper evaluation and management of the FVII deficiency. In our study, we found three homozygous patients, two of them had consanguineous parents, while the third patient was an adopted child with no available records regarding his family of origin. We also characterized molecular changes in two compound heterozygous and three heterozygous patients.

Mutation detection in patient 2 revealed the $10824 \mathrm{C}>\mathrm{A}$ homozygous substitution that causes the P303T defect in FVII protein. This mutation was previously detected in an Iranian patient [16]. It has been shown that residues P303, L305 and M306 are involved in tissue factor (TF) binding [17].

Another homozygous mutation was found in patient 5, C91S that was previously identified in an English patient [18]. Since C91 is engaged in disulfide bond formation, this mutation could be a basis of severe dysfunction of the enzyme. However, patient 5 did not exhibit severe complications such as hemarthrosis or gastrointestinal bleeding. Further studies are needed to explore the role played by different factors in determining the phenotypic variation of each mutation.

The highest prothrombin time (PT) and partial thromboplastin time (PTT) (34 and 44 min., respectively) were found in patient 6 homozygous for a rather frequent gene defect, the R304Q mutation. The R304Q mutation was first found in a heterozygous state in a patient with no clinical bleeding tendency by O'Brien et al. [19]. Variability in the degree of severity and phenotypic expression is commonly observed in patients with R304Q mutation. This mutation was found in symptomatic patients from Latin America, but the patients from Germany were asymptomatic while carrying R304Q [11]. This kind of variations in phenotypic outcome of a given genotype can be affected by environmental factors and genetic modifier loci. Previous studies revealed that the substitution R304Q had adverse effects on the enzyme's activity and TF interaction [19]. We also detected the R304Q variation in Patient 8 . He was identified as a compound heterozygote for R304Q as well as IVS7 $+7 \mathrm{~A}>\mathrm{G}$ alterations. The IVS7 $+7 \mathrm{~A}>\mathrm{G}$ is a common mutation reported in various populations $[20,21]$. It has been shown that IVS7+7A $>\mathrm{G}$ was responsible for the lowest relative FVII levels although they did not observe any changes in the mRNA structure [21]. We also detected the IVS7+7A $>\mathrm{G}$ transcript with a normal pattern in this patient.
Another compound heterozygous case in our study was patient 7 . Both mutations in this patient were located on exon 8, S282R and H348R. The mutation S282R was reported previously by Peyvandi et al. [22] in a compound heterozygous Iranian patient, while the other defective allele remained "unknown." H348R was previously reported in homozygous and compound heterozygous Indian patients $[23,24]$.

As stated earlier, some individuals with heterozygous F7 mutations may show bleeding manifestations. In our study, two patients were heterozygous for A244V transition, which was associated with decreased FVII activity levels. A244V was previously reported by Tamary et al. [25] in Iranian-Jewish patients with an allele frequency of 1:40. They detected a heterozygous A244V substitution in 10 out of 23 symptomatic patients affected by this mutation [25].

The only asymptomatic patient that we tested was patient 4, a 54-year-old man diagnosed on pre anesthesia blood analysis. Further molecular investigation revealed a heterozygous genotype with the $64 \mathrm{G}>\mathrm{A}$ missense mutation. This mutation was previously reported in a Turkish family [26]. The $64 \mathrm{G}>\mathrm{A}$ is located at the last nucleotide of exon $1 \mathrm{a}$ and is known as $\mathrm{V}(-39) \mathrm{I}$ or $\mathrm{V}(-17) \mathrm{I}$. As reported by Wulff and Herrmann [26], the homozygous form of this mutation could cause the severe manifestations such as postpartal (after birth) cephalic hematomas. It should be noted that in communities with a preference for consanguineous marriages, mutation detection of asymptomatic or mild cases could be of great importance in genetic counseling. The cDNA sequencing revealed no expression of mRNA carrying the 64A allele. This may be due to inefficient splicing or mRNA decay. However, the F7 cDNA sequencing in A244V, S282K, H348Q and R304Q implied that their transcripts were expressed at detectable levels. Therefore, it could be concluded that the reduction of FVII protein activity following these mutations is not related to the changes at mRNA level.

In conclusion, in the present study, we found eight different $F 7$ gene mutations, four of them were the first to be reported from Iran. This report reinforces the genetic and phenotypic heterogeneity of FVII deficiency, and provides evidence regarding the expression of the pathogenic mutations at the mRNA level. We propose that the reduction of FVII protein activity subsequent to missense mutations does not reflect the degradation of mRNA. We also wanted to bring the mutation detection in asymptomatic patients to the attention of genetic counselors. 


\section{ACKNOWLEDGMENTS}

This study was supported by a Grant No. 90004948 from the Iran National Science Foundation (INSF) to SS.

Declaration of Interest. The authors report no conflicts of interest. The authors alone are responsible for the content and writing of this article.

\section{REFERENCES}

1. Pfeiffer RA, Ott R, Gilgenkrantz S, Alexandre P. Deficiency of coagulation factors VII and X associated with deletion of a chromosome 13 (q34). Evidence from two cases with 46,XY,t(13;Y)(q11;q34). Hum Genet. 1982; 62(4): 358-360.

2. Lapecorella M, Mariani G; International Registry on Congenital Factor VIID. Factor VII deficiency: Defining the clinical picture and optimizing therapeutic options. Haemophilia. 2008; 14(6): 1170-1175.

3. O’Hara PJ, Grant FJ, Haldeman BA, Gray CL, Insley MY, Hagen FS, et al. Nucleotide sequence of the gene coding for human factor VII, a vitamin K-dependent protein participating in blood coagulation. Proc Natl Acad Sci USA. 1987; 84(15): 5158-5162.

4. Hagen FS, Gray CL, O’Hara P, Grant FJ, Saari GC, Woodbury RG, et al. Characterization of a cDNA coding for human factor VII. Proc Natl Acad Sci USA. 1986; 83(8): 2412-2416.

5. Berkner K, Busby S, Davie E, Hart C, Insley M, Kisiel W, et al. Isolation and expression of cDNAs encoding human factor VII. Cold Spring Harb Symp Quant Biol. 1986; 51(Pt 1): 531-541.

6. Nakagaki T, Foster DC, Berkner KL, Kisiel W. Initiation of the extrinsic pathway of blood coagulation: Evidence for the tissue factor dependent autoactivation of human coagulation factor VII. Biochemistry. 1991; 30(45): 10819-10824.

7. Napolitano M, Siragusa S, Mariani G. Factor VII deficiency: Clinical phenotype, genotype and therapy. J Clin Med. 2017; 6(4): 38.

8. Sevenet PO, Kaczor DA, Depasse F. Factor VII deficiency: From basics to clinical laboratory diagnosis and patient management. Clin Appl Thromb Hemost. 2017; 23(7): 703-710.

9. Mumford AD, Ackroyd S, Alikhan R, Bowles L, Chowdary P, Grainger J, et al. Guideline for the diagnosis and management of the rare coagulation disorders: A United Kingdom Haemophilia Centre Doctors' Organisation guideline on behalf of the British Committee for Standards in Haematology. Br J Haematol. 2014; 167(3): 304-326.

10. Mariani G, Bernardi F. Factor VII deficiency. Semin Thromb Hemost. 2009; 35(4): 400-406.

11. Herrmann FH, Wulff K, Auerswald G, Schulman S, Astermark J, Batorova A, et al. Factor VII deficiency: Clinical manifestation of 717 subjects from Europe and Latin America with mutations in the factor 7 gene. Haemophilia. 2009; 15(1): 267-280.

12. McVey JH, Boswell E, Mumford AD, Kemball-Cook G, Tuddenham EG. Factor VII deficiency and the FVII mutation database. Hum Mutat. 2001; 17(1): 3-17.

13. Cramer TJ, Anderson K, Navaz K, Brown JM, Mosnier LO, von Drygalski A. Heterozygous congenital Factor VII deficiency with the 9729 del4 mutation, associated with severe spontaneous intracranial bleeding in an adolescent male. Blood Cells Mol Dis. 2016; 57: 8-12.

14. Castaman G, Plate M, Giacomelli SH, Rodeghiero F, Duga S. Alterations of mRNA processing and stability as a pathogenic mechanism in von Willebrand factor quantitative deficiencies. J Thromb Haemost. 2010; 8(12): 2736-2742.

15. Shahbazi S, Baniahmad F, Zakiani-Roudsari M, Raigani M, Mahdian R. Nonsense mediated decay of VWF mRNA subsequent to c.7674-7675insC mutation in type 3 VWD patients. Blood Cells Mol Dis. 2012; 49(1): 48-52.

16. Peyvandi F, De Cristofaro R, Garagiola I, Palla R, Akhavan S, Landolfi R, et al. The P303T mutation in the human factor VII (FVII) gene alters the conformational state of the enzyme and causes a severe functional deficiency. Br J Haematol. 2004; 127(5): 576-584.

17. Persson E, Kjalke M, Olsen $\mathrm{OH}$. Rational design of coagulation factor VIIa variants with substantially increased intrinsic activity. Proc Natl Acad Sci USA. 2001; 98(24): 13583-13588.

18. Millar DS, Kemball-Cook G, McVey JH, Tuddenham EG, Mumford AD, Attock GB, et al. Molecular analysis of the genotype-phenotype relationship in factor VII deficiency. Hum Genet. 2000; 107(4): 327-342.

19. O’Brien DP, Gale KM, Anderson JS, McVey JH, Miller GJ, Meade TW, et al. Purification and characterization of factor VII 304-Gln: A variant molecule with reduced activity isolated from a clinically unaffected male. Blood. 1991; 78(1): 132-140. 
20. Giansily-Blaizot M, Flory-Pigagniol L, Favier R, Farah RA, Martin-Toutain I, Verdy E, et al. Accurate characterization of the IVS7 repeat polymorphism of FVII gene and identification of three novel allelic forms. Thromb Haemost. 2006; 96(1): 95-97.

21. Pinotti M, Toso R, Girelli D, Bindini D, Ferraresi P, Papa ML, et al. Modulation of factor VII levels by intron 7 polymorphisms: Population and in vitro studies. Blood. 2000; 95(11): 3423-3428.

22. Peyvandi F, Jenkins PV, Mannucci PM, Billio A, Zeinali S, Perkins SJ, et al. Molecular characterisation and three-dimensional structural analysis of mutations in 21 unrelated families with inherited factor VII deficiency. Thromb Haemost. 2000; 84(2): 250-257.

23. Ahmed RP, Biswas A, Kannan M, Bhattacharya M, Geisen C, Seifried E, et al. First report of a FVII- deficient Indian patient carrying double heterozygous mutations in the FVII gene. Thromb Res. 2005; 115(6): 535-536.

24. Mota L, Shetty S, Idicula-Thomas S, Ghosh K. Phenotypic and genotypic characterization of Factor VII deficiency patients from Western India. Clin Chim Acta. 2009; 409(1-2): 106-111.

25. Tamary H, Fromovich Y, Shalmon L, Reich Z, Dym $\mathrm{O}$, Lanir $\mathrm{N}$, et al. Ala244Val is a common, probably ancient mutation causing factor VII deficiency in Moroccan and Iranian Jews. Thromb Haemost. 1996; 76(3): 283-291.

26. Wulff K, Herrmann FH. Twenty two novel mutations of the factor VII gene in factor VII deficiency. Hum Mutat. 2000; 15(6): 489-496. 